\title{
Layoffs and Downsizing Implications for the Leadership Role of Human Resources
}

\author{
Bahaudin G. Mujtaba ${ }^{*} \stackrel{\oplus}{ }$, Tipakorn Senathip ${ }^{2}$ \\ ${ }^{1}$ Nova Southeastern University, Fort Lauderdale, FL, USA \\ ${ }^{2}$ Ramkhamhaeng University, Bangkok, Thailand \\ Email: *mujtaba@nova.edu, tipakorn.senathip@gmail.com
}

How to cite this paper: Mujtaba, B. G., \& Senathip, T. (2020). Layoffs and Downsizing Implications for the Leadership Role of $\mathrm{Hu}-$ man Resources. Journal of Service Science and Management, 13, 209-228.

https://doi.org/10.4236/jssm.2020.132014

Received: January 18, 2020

Accepted: March 28, 2020

Published: March 31, 2020

Copyright $\odot 2020$ by author(s) and Scientific Research Publishing Inc. This work is licensed under the Creative Commons Attribution International License (CC BY 4.0).

http://creativecommons.org/licenses/by/4.0/

\begin{abstract}
Downsizing or laying off employees is usually the strategically planned elimination of large numbers of personnel or workforce to enhance organizational effectiveness and economic outlook. Downsizing has some temporary or immediate advantages such as boosting profits, avoiding bankruptcy, creating new relationships, re-organization, and getting rid of "deadwood" or disengaged employees. The disadvantages of layoffs or downsizing in an organization can include reduced skilled workers and low morale, as the employees experience mixed emotions, dismay, stress, guilt, or even envy. In addition, layoffs can reduce existing employees' satisfaction and commitment to the organization, which can result into lower performance. Human resources (HR) professionals and managers must effectively manage the impact of layoffs on people. The immediate financial hardship of a layoff could affect both the physical and psychological well-being of an individual worker, while also causing bankruptcy, depression, and more severe illnesses. Layoffs could result into long-term impacts since unemployment can last up to six months or longer. There might also be experiences of hopelessness when laid off employees are having difficulty finding new employment. This article provides an overview of layoffs as well as their impact on employees. In addition, the paper explains the role of HR personnel throughout layoffs, which are to ensure that the organization is able to enhance its overall effectiveness. In their role as project managers who are leading the layoff process, human resources professionals must focus on the legal, ethical, and socially responsible implementation of transitioning people and the organizational culture. Furthermore, managers can introduce new technologies or robots to reduce the need for large numbers of employees in the future, and they might consider changing location of the business or organization to be closer to the relevant material resources while better serving customers.
\end{abstract}




\section{Keywords}

Layoffs, Reduction-In-Force, Downsizing, Role of HR, Rightsizing, Ethical Implications

\section{Introduction}

A layoff, or cessation of workers employment, is at times a temporary suspension but often a permanent termination of employees from their jobs in the organization. Layoffs and downsizing decisions are not necessarily caused by any specific fault of the employees, but are usually a consequence of decreasing sales or customers, cash, and/or material resources within the organization. Many times, companies decide to lay off some of their non-essential personnel during economic slowdowns to avoid bankruptcy. Mergers also can cause layoffs, as firms try to convert their organizational cultures into lean operations. A layoff can be a consequence of mismanagement or faulty administration that was not able to keep the company afloat. Layoffs can be a consequence of declining industries (such as mining, steel, railway, newspaper, etc.). Cutting costs through outsourcing has in the past been a factor that caused companies to lay off large numbers of employees. Plain downsizing, another form of organizational restructuring, also causes lay-offs. Layoffs are one of the mechanisms companies use as short-term solutions to lower labor costs (Telford, 2018; Travaglione \& Cross, 2006; Petzall, Parker, \& Stoeberl, 2000; Jordan \& Zitek, 2012; Kokemuller, 2017).

The term "layoff" is synonymous with and often associated with concepts such as reduction-in-force (RIF), downsizing, rightsizing, termination, firing, reengineering, restructuring, and voluntary separation options (VSO) when a large number of workers' employment is being discontinued with an organization. Organizational layoffs are designed to improve productivity, economic outlook, and overall competitiveness, and they are often perceived as the only way to save companies from bankruptcy (Neto, 2018). When layoffs are announced, it can be a huge disappointment to those who are immediately impacted by it. For example, right after the Thanksgiving Holiday (November 26, 2018), General Motors (GM) announced that it would close five manufacturing facilities and lay off around 15,000 workers. According to the company, these closings and layoffs will help them save about $\$ 6$ billion each year as they shrink their management ranks while terminating the employment of thousands of American and Canadian production workers (Lynch \& Telfor, 2018). As can be seen from Table 1, less than a decade ago, GM had announced the layoff of around 47,000 employees in 2009 (Zillman, 2015). While such layoffs might be necessary for survival and/or competiveness, it has a devastating impact on working adults who have to provide for their family members.

While some workers today feel that immigration is a threat to their jobs, many are ignoring the dangers of modern technology or automation, which has greatly 
Table 1. Major layoffs of the past few decades.

\begin{tabular}{ccc}
\hline Company/Organization & Layoff Year & Number Downsized \\
\hline Oil/Gas Industry (global) & $2015-2016$ & 350,000 \\
IBM & July 1993 & 60,000 \\
Citigroup & Nov. 2008 & 50,000 \\
Sears Roebuck \& Co. & Jan. 1993 & 50,000 \\
General Motors & Feb. 2009 & 47,000 \\
AT \& T & Jan. 1996 & 40,000 \\
Ford Motor Co. & Jan. 2002 & 35,000 \\
Kmart Corp. & Jan. 2003 & 35,000 \\
Circuit City Stores & Jan. 2009 & 34,000 \\
Boeing Co. & Sept. 2001 & 31,000 \\
Bank of America & Sept. 2011 & 30,000 \\
Hewlett-Packard & Sept. 2015 & 28,000 \\
General Motors & Dec. 2018 & 15,000 \\
\hline
\end{tabular}

increased output and productivity in the developed economies. Trade among countries is another variable as firms usually outsource jobs to cheaper markets in terms of labor cost as well as for tax purposes. For example, AT \& T has closed 44 call centers in the last decade and the jobs went offshore where workers are often paid around $\$ 2$ per hour, compared to over $\$ 10$ in the United States (Sainato, 2018). This outsourcing of jobs can create poor working conditions for the emerging market countries without adequate labor protections. In the past, we have seen outsourced jobs sometimes completed by young teenagers and children that were working in factories with sub-standard conditions. Similarly, outsourcing jobs to lower-cost labor markets always makes existing employees wonder about when their jobs will be going to new markets or automated by technology.

Regardless of the cause, in today's workplace layoffs have become commonplace as organizations actively seek ways in which to reduce expenses and optimize labor costs. Due to economic challenges, layoffs are often viewed as an initial course of action within organizations, the rationale being to improve immediate company profitability and reduce costs. While some executives and managers might be tempted to jump on the bandwagon of quick cost reductions through layoffs, Cunningham (2016), in the article entitled "After 350,000 Layoffs Oil Companies Now Face Worker Shortages," emphasizes that the economy can easily turn around; therefore, decision-makers should think twice before letting experienced human resources leave the organization. Slav (2016) advises that the oil and gas industry's global layoffs of 350,000 workers in 2016 was heavily influenced by the temporary ups and downs of prices and production (supply and demand); consequently, laying off too many people too quickly can put firms in an awkward position of having to rehire workers, if they are not patient, careful and strategic in their decision-making. A sample of layoffs in the oil and gas industry during early 2016 is shown in Figure 1. 


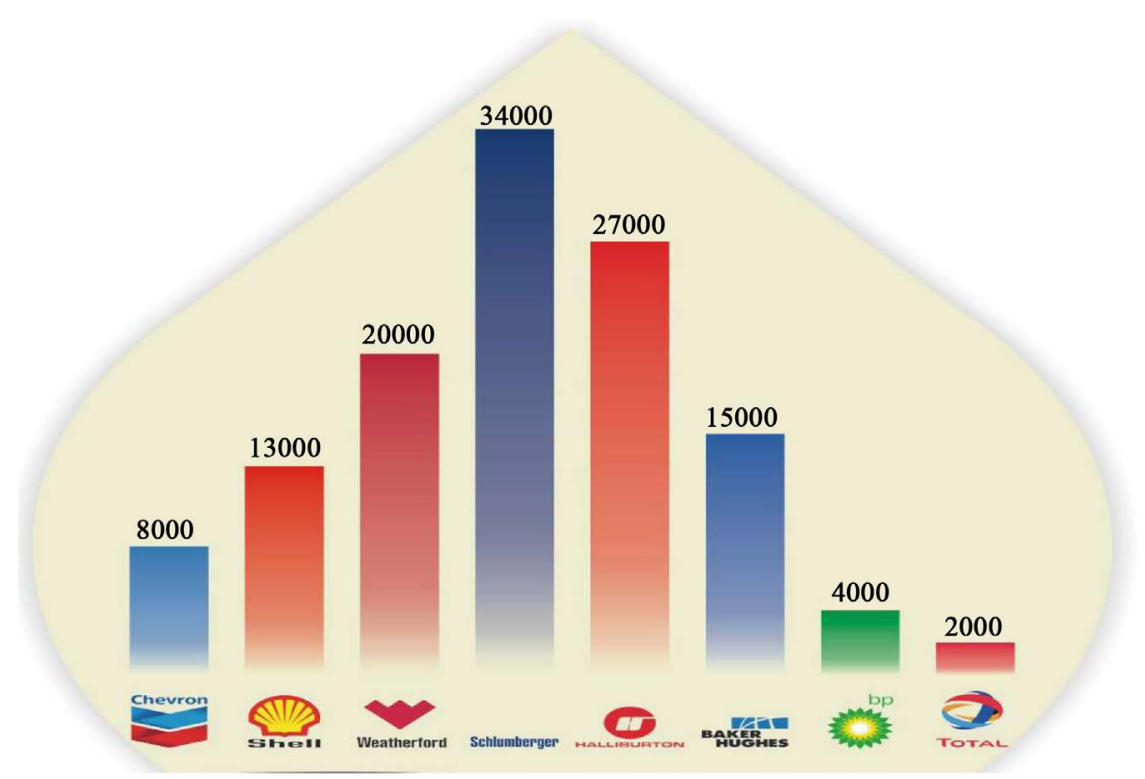

Figure 1. Layoffs in the oil industry in early 2016 (Slav, 2016).

Laying off employees, whether letting go of a single employee or conducting a group layoff, can be one of the most emotionally difficult tasks for management and human resources (Mujtaba, Ping, \& Jieqiong, 2013; Sarwar, Khan, \& Mujtaba, 2018). Given the associated emotional and financial strain a layoff can have on the employee and his/her family, it is vital that companies weigh the pros and cons of mandatory layoffs to ease emotional/financial pains and to avoid potential legal disputes.

While voluntary separation options (VSOs) do provide incentives for a required number of workers to leave the organization so that the firm can meet its fiscal budget requirements, layoffs do not provide options and are usually imposed on workers without any flexibility of taking a reduced salary or an extended vacation. It is important for managers and employees to distinguish between firing and laying off employees. Firing refers to employee termination based on any valid or rational economic reason. Unfairly firing a person from a job often makes workers feel angry, confused, and/or lost and may lead into depression because of feeling helpless over what to do next in life (Bennett \& Moehring, 2015). However, laying off refers to employee termination based on company economics, to avoid bankruptcy, and/or for overall competitiveness. The main purpose of layoffs is maintaining profitability of the company through reduction of the workforce in the organization (George, 2014). During difficult economic times in the company, laying off employees can be a cost-effective method of maintaining productivity while at the same time increasing profits (Schmitt, Borzillo, \& Probst, 2012).

On a periodic basis, we learn about a new company laying off a significant portion of its labor force in order to cut cost, to avoid bankruptcy, to boost profits, and/or to reinvent its business model. These layoff decisions tend to have severely damaging effects on the business needs of an organization along with 
negative consequences for the lives of those that are laid off, downsized, terminated, demoted, and/or moved into a lateral position in a remote destination. This unforgiving reality of layoffs further amplifies the need for companies to fully research and plans all options prior to implementing a downsizing policy of reduction in force. Managers and HR professionals must consider all the positive and negative aspects that will come from implementing any layoff plans. Proper research regarding the pros and cons will demonstrate to shareholders that the company is taking the necessary precautions to ensure that it will remain successful in the end. Even with the negative publicity surrounding a reduction in force or downsizing decision, companies continue to utilize these measures as a strategic step forward.

Although making the decision to dismiss an employee is rarely easy, organizational leaders should carefully weigh the pros and cons of reducing the workforce. Companies should first consider all available alternatives to layoffs such as extended vacations, reduced salaries, furloughs, putting a freeze on all "hiring and promotion," and/or reducing authorized overtime. Given the various risks, organizations should carefully consider whether they need to conduct layoffs, and if so, can they implement such a downsizing decision in a legal, ethical, and socially responsible manner.

\section{Rationale for Layoffs}

Layoffs seem to be more and more common as an initial step for avoiding bankruptcy, or to boost profits. Therefore, layoffs are an unfortunate reality of the modern workplace locally, nationally and internationally. According to Noe, Hollenbeck, Gerhart and Wright (2018: p. 197), while people tend to believe that downsizing is something that a company implements in difficult times of recession or when facing bouts or stretches of poor performance, but in fact, "many companies that are doing quite well still downsize for strategic reasons." Organizations choose the option of layoffs, reduction in force, or downsizing for several reasons: "many organizations are looking to reduce costs, and because labor costs represent a big part of a company's total costs, this is an attractive place to start" (Noe et al., 2018: p. 197). In order to remain competitive in the market, companies look to cut costs in any area of their business that they can, including its human resources. Depending upon the quantity and quality of the company's workforce, reducing labor costs is one of those areas where firms can significantly lower its expenses quickly. This reduction in force might only give the firm a temporary competitive advantage to avoid bankruptcy as with fewer labor expenses a company can sell its products at a lower price than competitors; thereby giving it the opportunity to increase market share.

As technology continues to develop and provide cost effective options, global leaders and managers will continue to explore innovations and diverse organizational leadership structures in order to gain a competitive advantage (Mujtaba, 2019). The introduction of new technologies can reduce the need for a large number of employees. As we can see from historical data of the past four dec- 
ades, technological advancements have negatively affected manufacturing and industrial workers by providing fast automation at reduced cost for repetitive tasks. In most cases, the rationale for deciding to downsize is straightforward: by reducing costs, executives hope to improve firm profitability (Ramlall, Al-Sabaan, \& Magbool, 2014). Some of the pros (rationale/reasons) and cons (possible externalities or unintended side effects) of layoffs are in Table 2.

Another reason why firms are laying off workers is to shift manufacturing or other business needs to an overseas location where products can be completed with cheaper resources. Consequently, jobs are moving from one country to another that is closer to the resources needed at cheaper rates, resulting in downsizing in the nation that exports the jobs. While these practices may have positive short-term effect on reducing labor costs, they can, at least temporarily, compromise efficiency in customer service due to cultural differences, and in speedy manufacturing since laws vary internationally.

Ultimately, we can summarize the benefits or advantages of a layoff as follows:

- Enables human resources professionals and managers to ensure that the company has the best employees on its team. Layoffs allow the company to purge itself of those disengaged or "dead wood" employees that are not making a meaningful contribution. Accordingly, companies have the opportunity to closely analyze the performance of their employees and determine which workers should stay (Reddy, 2018).

- Allows the company to get rid of redundant jobs. Because organizations are being asked to work leaner and more efficiently while developing growth and innovation, layoffs can serve as a strategy to ensure that companies are aware of the critical responsibilities for each position. This will give companies an opportunity to perform a proper analysis and job design so that there is no unnecessary duplications or waste (David, 2011).

Table 2. Pros and cons of layoffs.

\begin{tabular}{|c|c|}
\hline Pros of Layoffs (Reasons) & Cons of Layoffs (Externalities) \\
\hline $\begin{array}{l}\text { Increasing profits, economic outlook, } \\
\text { and overall company competitiveness. } \\
\text { - Cutting costs by reducing employee } \\
\text { benefits and liability. } \\
\text { - Laying off high paid employees } \\
\text { and replacing them with } \\
\text { lower paid employees. } \\
\text { - Getting rid of disengaged workers } \\
\text { that cannot "pull their own weight" } \\
\text { (“dead wood”) and simply increase } \\
\text { workload for other employees. } \\
\text { - Stockholders might receive a better } \\
\text { return on their investments. } \\
\text { - Strategically planned layoffs lead to } \\
\text { smarter organizations when tasks } \\
\text { are properly revamped and } \\
\text { reassigned (Mannino, 2010). }\end{array}$ & $\begin{array}{l}\text { - } \text { Existing employees might be in a bind when } \\
\text { knowledgeable and skilled workers are laid off. } \\
\text { Consequently, customer service may suffer. } \\
\text { - Current workers and laid off employees may } \\
\text { risk suffering from occupational, } \\
\text { psychological and other health issues } \\
\text { - Limited employees within a } \\
\text { company/department may lead to more } \\
\text { unhappy workers, which in turn may } \\
\text { lower company revenue. } \\
\text { Laying off skilled workers may slow } \\
\text { down production damage quality } \\
\text { within the company. } \\
\text { Attitudes become negative because } \\
\text { employee thoughts of the possibility } \\
\text { of easily being replaced and just being } \\
\text { a number to the company. }\end{array}$ \\
\hline
\end{tabular}


- Provides an opportunity to change the culture of the organization. Most executives agree that the organization's culture drives workplace productivity, creativity, profitability, firm value, and even growth rates. As such, layoffs can give the company a chance to not only retain its best employees, but to also develop an organizational culture that is comprised of the right attitudes, values, and talent aimed at ensuring that the company is competitive.

- Causes employees to become engaged and more productive. As the company begins to build a new culture for the future, leaders must encourage their people to take ownership of their time to eliminate unnecessary work, and to be creative in continuous improvement (Perlman, 2014).

- Helps to reduce labor costs. Most organizations are looking to reduce costs, and because payroll is considered a liability on the balance sheet, having the right employees can make the company leaner and more competitive (Reddy, 2018). The costs or disadvantages of layoffs can include:

- Causes remaining employees to have more responsibilities. While specific positions are eliminated during a downsizing, the quantity of work generally remains consistent. Remaining employees are saddled with additional responsibilities and requirements that can affect the amount of work they are expected to perform. If not managed properly, the added stress due to workload increases can erode any productivity boost (Acevedo, 2017).

- Many employees may have a low morale because of fear of losing their jobs. Downsizing and layoffs introduce many different changes in an organization including a change in how comfortable and secure employees feel about their job within the organization (Heathfield, 2019). Accordingly, employees may abandon the commitment to their employer because of loss of trust and fear that their job is also at stake. Bruno (2008) explained that while the morale and productivity of remaining employees will be affected if they feel that the layoffs were handled badly, it may also end up limiting its revenue growth, as well.

- High human suffering. Downsizing activities may financially and psychologically negatively affect employees or a significant percentage of a company's staff.

- Loss of specialized skills and knowledge. Laid off employees retain knowledge that is often lost during downsizing. As such, laying off skilled workers can also leave companies in a bind once the climate does get back to normal having to hire and retrain new workers can put a business at a competitive disadvantage (Bruno, 2008).

- Remaining employees might start exploring their options of working elsewhere. After a layoff, no employee totally relaxes; they are waiting for the next round of downsizing or cost-cutting layoffs, which may include them (Heathfield, 2019).

\section{Impact of Layoffs on People}

It is true that a reduction in force or downsizing can provide strategic benefits, 
but it can also create negative circumstances that will damage the overall efficiency of the organization. For many companies where downsizing is not handled properly regarding motivation and morale of the remaining staff, it can disturb the commitment and productivity of its workforce, which in turn will affect revenues and bottom-line profits. The reality is that downsizing leads to the loss of experienced talent, and it disrupts the social networks needed to promote creativity and flexibility within the organization's culture. This can significantly hamper the company from moving forward unless management is able to immediately adjust to the deficiencies by redesigning jobs and implementing new technology to offset the loss of talent.

Industries that rely on the timely manufacturing of their products and engage in significant customer contact will be affected the most. Another negative effect of a poorly planned downsizing is that many times companies let go of experienced and talented individuals that are critical to their success. Some managers and firms let go of workers who are irreplaceable due to their accumulated and specialized expertise. When this happens, the blame should fall on the managers, executives, and human resources personnel who clearly do not understand the skillsets and talents of their existing workforce. Prior to implementing a downsizing policy, managers need to specifically evaluate and outline which employees need to be laid off and which ones need to remain in order for the business to continue operating as smoothly as possible. Unfortunately, many companies seem to terminate employees indiscriminately or based on higher salary levels, and as a result, face the consequences of severely weakening their skilled talent pool, thereby damaging immediate sales, and eventually reducing profits.

Another aspect of layoffs that does not get much traction when it comes to downsizing is in regards to those employees that remain with the organization. The workers that are not let go may suffer from "survivor's remorse" which can severely damage their work ethic and overall company commitment, since the "employees who survive the purges often become narrow minded, self-absorbed, and risk averse" (Noe et al., 2018: p. 199). The shock of seeing so many talented colleagues and friends lose their jobs can have a significant negative impact on everyone's motivation and overall attitude (Mujtaba, 2014). Once this type of shock sinks into the culture of the organization, employee morale and job commitment can plummet, when not managed effectively by managers and human resources professionals.

Managers must be aware that layoffs and downsizing can have undesirable effects on those individuals that are terminated from the company as the lack of pay, health benefits, and meaningful work has negative implications for financial, physical, and even psychological aspects of human beings, causing bankruptcies, illnesses, and severe depression (Kurebwa, 2011; Datta, Guthrie, Basuil, \& Pandey, 2010). Some individuals will unfortunately have a difficult time adjusting to life after being let go, especially those who have been working with the company for a long period of time. Generally, depression, anxiety, and lack of confidence are common struggles for victims of layoffs. In some cases, these 
feelings of despair can become chronic mental health conditions that adults will battle for the rest of their lives. The situation becomes even grimmer for those adults that are the primary "breadwinners" (wage earners) for their families. It can also be extremely challenging for those who live on a limited budget and "paycheck to paycheck." Downsizing can be an extremely difficult and unfortunate circumstance that might seem insurmountable for some adults to overcome. One study (Cappelli, Bassi, Katz, Hnoke, Isterman, \& Useem, 1997) found that stress-related illnesses were $50 \%$ higher in the companies that had downsized their workforce compared to those companies that had not undergone downsizing. Furthermore, cases of employee burnout were more than twice as high at companies that had downsized compared with those that had not. Since work provides structure for one's time, social connectedness, feelings of self-worth, and the valued role of being a "breadwinner" in the family, losing one's job entails confronting the losses associated with such social and psychological benefits (Ramlal, Al-Sabaan, and Magbool, 2014). As such, involuntary job loss or layoffs are stressful and can have a negative impact on mental health of those who are impacted by it (Latack, Kinicki, \& Prussia, 1995). A major factor that contributes to the failure of most organizations to achieve their corporate objectives after major layoffs or downsizing is that they do not adequately and effectively address the "people factor" throughout the process as it relates to the surviving employees (Appelbaum, Delage, Labib, \& Gault, 1997).

Aside from the short-term effects and damages, downsizing can also affect an individual's long-term plans through the negative stereotypes that are attached to it, especially for older workers who are often discriminated against in acquiring new employment. Research has demonstrated that even when layoff victims can survive the immediate challenges, in the long term, an extended stretch of unemployment (lasting over six months) can negatively stigmatize the individual, further reducing future opportunities (Noe et al., 2018: p. 197). For most adults, it is difficult enough to get a job even without the stigma of being laid off from one's tenured employment. This difficulty increases exponentially for individuals that are let go as many are left wondering when their next opportunity for employment will come as they go from interview to interview. In order to offset prolonged periods of unemployment, most adults will search for any type of work, including entry-level part-time positions and volunteer opportunities, in order to boost their chances of steady employment. Unfortunately, a prolonged lack of success in being rehired may cause some individuals to give up looking for employment, which further decreases their self-confidence, intrinsic motivation, and self-worth.

Layoffs can take a heavy toll on both employees and their family members. A newly laid-off employee can experience feelings of anger, irritability, vulnerability, rejection, and helplessness. These negative emotions can also spread amongst loved ones, creating long-term hardships for those who are terminated as part of the rightsizing or downsizing policies. Even though there is no clear-cut or linear step-by-step process in which a laid-off employee deals with 
the challenges of being let go, the emotional, social, financial, and physical impacts are some of the hardships that these adults might experience (Kurebwa, 2011; Datta, Guthrie, Basuil, \& Pandey, 2010; Mujtaba \& McCartney, 2010):

- Emotional impact: We know that the workplace serves as a primary source for forming social connections with other professionals in an industry. Furthermore, work serves as a way of contributing to the society. After losing one's social connections and/or means of professional contribution, terminated employees may experience feelings of anger, helplessness, and other negative emotions as workers become uncertain of the future and their new reality of unemployment.

- Social impact: Layoffs can have a devastating impact on an employee's personal and professional relationships. If a laid-off employee's main circle of friends includes those who remain employed with the company, then it might cause unwanted tension within his/her circle of former colleagues. Also, the laid off employee's spouse may wonder how he/she should comfort the husband or wife. Additionally, if unemployment status lasts for a significant period the employed partner may display signs of resentment and question whether the laid off employee is working hard enough to find a new job.

- Financial impact: It is clear that expected layoffs will lead to financial burden for many employees, both short-term and long-term. Sudden change in employment status can have a detrimental impact on the household as it may lead to unwanted debt and physical/mental strain on one's spouse. Additionally, any new employment may not be comparable, especially if the worker receives significantly reduced wages, causing further difficulties for struggling workers to maintain the family's overall quality of life.

- Physical impact: Losing employment can also lead to long-term physical as well as psychological health problems. Sudden loss of a job increases levels of stress and anxiety. Additionally, lack of employment can lead to loss of interest in outside activities and a depressed mood. A sudden increase in stress, anxiety, and depressive behavior can lead to chronic physical conditions such as heart disease, gastrointestinal disorders, and high blood pressure.

Seeking support, thinking positively, and other coping actions to find a new job will increase the morale of the laid-off employee; and on the opposite side, disengagement and psychological separation will cause the individual to suffer physically and emotionally, making it more difficult to find a new job. Wage loss is another significant effect that displaced and laid off workers suffer from both in short-term and long-term. In situations of layoffs, in order to obtain some kind of income, individuals often accept lower paying jobs outside of their profession and industry to keep busy and contribute to society. Table 3 provides some general suggestions for workers who lose their job as part of downsizing or restructuring policy.

\section{The Role of HR in Layoffs}

When there are layoffs, companies can run into legal issues with some of the 
Table 3. Suggestions for laid-off employees.

If you have lost your job, the following are some thoughts, suggestions, and activities to do as part of your transition to a new responsibility.

1) Acknowledge the reality of losing your position.

2) Note that being laid off is not necessarily your fault, so do not feel guilty about it.

3) Let your family members and friends know that you are not working.

4) If you feel upset, disappointed, frustrated, and angry, then acknowledge it as it is normal.

Learn to manage your emotions constructively and productively. The reality is that you

lost a position, not your profession.

5) Be patient and strategic with your time off by doing what you enjoy the most.

6) Exercise; take care of your health and develop productive hobbies.

7) Socialize; connect with "long-lost" friends, colleagues and family members.

8) Be frugal; save your funds for a "rainy" day.

9) Review your skills/experiences, update your resume, and begin thinking of your next opportunities.

10) Network and send resumes out for many possible jobs while meeting with experts in your profession.

11) Read published books, articles and trade industry news every day for at least one hour to stay updated in your profession and field of expertise.

12) As you wait for the next opportunity, become a micropreneur by capitalizing

on your existing skills as a part-time business owner, contractor, and/or consultant.

employees that were laid off, especially if a large number of them are from any protected minority-status categories based on gender, race, religion, age, etc. (Cavico, Mujtaba, \& Muffler, 2016; Cheretis \& Mujtaba, 2014; Mujtaba, 2010). During layoffs, companies can face potential discrimination lawsuits if the layoffs are not supported by solid data to support the financial or economic benefits in a clear and transparent manner. Lawsuit settlements or defense of legal claims can get expensive and further hurt an organization (Kokemuller, 2016; Cavico \& Mujtaba, 2014). It should be noted that the human resources department is morally, legally and formally tasked with the responsibility of hiring, compensating, training, developing, monitoring, retiring, coaching/counseling, and selecting the right positions and/or employees to be laid off when the organization has to reduce its workforce (Liu, Gong, Zhou, \& Huang, 2017). Human resources professionals can play a particularly important role in the strategic planning and implementation of employee layoffs. HR professionals are often tasked with the job of weighing the pros and cons of downsizing. According to experts, "the HRM function must 'surgically' reduce the workforce by laying off the workers who are less valuable in their performance" (Noe et al., 2018: p. 96).

The HR department plays a very prominent leadership and management role when it comes to the layoff process. HR should be heavily included in the strategic planning, implementation and overall supervision of this process. HR staff members have the responsibility of planning, executing and managing the layoffs to align with the business needs and to avoid the negative consequences. Every step of the way, HR should be involved in the pre-planning, initiations, announcement, implementation, supervision, and the after effects. According to the University of Washington (2018), human resources responsibilities can in- 
clude the following:

1) Evaluate the reasons for layoff to ensure that they are consistent with employment program or contract requirements.

2) Assist all managers with planning and managing complex layoffs.

3) Determine rehire list and/or bumping options for classified staff.

4) Ensure that the layoff notice is properly prepared and signed by the official who has the delegated authority to do so (typically the president or equivalent authorized official).

5) Ensure that the signed layoff notice is properly delivered to the employees.

6) Determine, for classified staff, that the employee's layoff option selection is properly recorded and acted on.

The human resources department is essentially the first to become aware of any major companywide change. They are the company's integral partners in carrying out plans as major as a layoff. HR should work closely with the leaders of the organization to bring structure and order to the anticipated operation.

Initially, one must identify specific problems that downsizing is expected to solve. Once these issues have been identified, then one must assess the resources that can be devoted to it. Although an organization may be motivated by the immediate reduction of financial burden, HR professionals must consider the long-term effects of downsizing along with its externalities. Part of the examination process involves exploring various viable alternatives. Immediate downsizing could potentially reduce the organization's ability to maintain high levels of productivity. Consequently, downsizing may prompt HR to outsource company jobs to employees who are willing to work for lower wages to temporarily aid in the transition process. However, these individuals are not always experienced and may hinder the quality of service and products produced. Therefore, HR's most important role in layoffs includes oversight and supervision of the process. Once an organization has decided to partake in the layoff process, HR should be made responsible for determining specific individuals to be laid off. Additionally, HR must review union provisions, collective bargaining agreements, and other local laws, when applicable, to determine financial obligations (i.e. severance packages) and notice requirements. In most cases, companies may have financial obligations to the workers who are being laid off, such as payment of accrued vacation and employee transition benefits.

At the outset of a layoff, the HR department professionals must realize that it is a painful process for all parties involved. By having this realization, they will be able to approach the process and remain objective while keeping in mind that specific positions are eliminated (not necessarily individuals). It is critical for HR to have a well-thought out plan that can be executed fairly, quickly, and properly. Each affected employee should be treated with respect in the manner in which the news is delivered. Preferably, a face-to-face conversation should take place, affording each employee an opportunity to ask questions and be informed of next steps. HR should consider if there are other roles within the organization that the employee can transfer into immediately. HR can also prepare severance 
packages that include career transition support benefits (Varelas, 2010). The communication should be clear and honest to avoid damaging rumors. HR must create plans to move the business forward while managing retention and engagement among the remaining employees. Managers should involve those that remain in shaping the future of the company and inquire what they need in order to do their jobs well, thus reassuring them of their role to avoid losing them through voluntary resignations (Varelas, 2010).

Downsizing causes high levels of stress, poor morale, and even guilt amongst surviving employees. Given the difficulty of the situation, HR should implement measures to instill confidence in the company, assure employees of their value to the organization, and communicate to all workers the company's reason(s) and rationale for the layoff. Most importantly, it is vital that the organization remain honest and open for communication with all individuals who are impacted by the reduction in force. Group dynamics and teamwork can be negatively altered if employees are not able to trust their managers and employer. Thus, it is important for HR to anticipate remaining employees' concerns and address them proactively and regularly.

One of the purposes of HR is to protect a business's finances, along with their employees so it can effectively serve all stakeholders as per the stated policies (Senathip, Mujtaba, \& Cavico, 2017; Wolf \& Mujtaba, 2011). While employees are usually laid off as a means to reduce costs, it should be noted that employers are still legally and ethically responsible for paying some unemployment benefits to the employees that are laid off (Cavico \& Mujtaba, 2013). According to research, laid off employees are usually without work for about 26 weeks (5 - 6 months) (SmartTalk HR, 2019). In addition, even while laid off workers are no longer employed by the company, social media has given way to promote positive relationships with former employees. Employees are the most significant asset and investment of any company, not only when they are employees but even afterwards. Building a positive relationship with employees from the moment they are candidates for the job through when they are no longer employed by the company will allow for positive brand recognition. Previous employees and candidates will always be potential rehires, referrals, and future opportunities for customer/partner relationships.

As evidenced thus far, the HR department can play a vital leadership role in various functions of an organization, especially in layoffs. Therefore, according to experts (Uhlig, 2017), it is HR's responsibility to:

1) Review the downsizing decision: HR's first responsibility should be to identify the specific problems that downsizing is to solve, and then assess the resources that can be devoted to it. In addition, HR must consider how downsizing will affect the company in the longer term.

2) Explore alternatives. It is HR's responsibility to explore all the available alternatives so that decision makers have all the facts needed to make the best possible judgement.

3) Present those alternatives to decision makers: It is HR's responsibility to 
provide decision makers with a detailed report highlighting their recommendations as well as the applicable benefits and implications of the decision.

4) Plan the downsizing process: Professionals should work with executives and managers to establish and document the criteria for deciding which employees should be laid off based on a fair and legal process consider critical skills as well as job performance.

5) Manage the process. HR professional must have supervision responsibilities for the layoff process and should keep employees in the loop. HR must explain the reasons and the anticipated effects of the restructuring and keep employees up to date on progress, while maintaining law and order.

6) Develop various strategies that will help remaining employees to cope after the downsizing process is complete, Downsizing causes poor morale, high levels of stress and even guilt among the remaining employees. HR professional should implement measures to instill confidence that the company and its employees will ultimately benefit from the changes (Uhlig, 2017).

Research indicates that surviving employees suffer the negative effects of downsizing just as profoundly as those who are laid off (Baruch \& Hind, 2000). Survivor syndrome is the emotional and attitudinal characteristics of those employees who have survived a downsizing (Mossholder et al., 2000). Research has shown that survivors exhibit a plethora of problems, such as de-motivation, cynicism, insecurity, demoralization, and a significant decline in organizational commitment (Baruch \& Hind, 2000). The emotional after-effects of fear, anger, frustration, anxiety, and mistrust on the part of the layoff survivors pose a real threat to performance and productivity as a smaller workforce is expected to perform an increasing number of responsibilities.

Overall, conducting a layoff is a difficult process under most circumstances and human resources department needs to have an active leadership role in managing it. Once the organization has strategically determined to layoff a part of its workforce to improve their financial situation, HR must plan and organize to carefully assess which employees will be laid off in accordance with the goal and relevant laws. Here it is important to make sure that no disparate impact can happen for happen for employees who are part of a protected class. Following this, employers need to determine if any of the labor union contract agreements or even local, state or federal laws will apply, in which case they need to follow the legal directives and provide relevant notice to affected employees. HR department might work on the establishment of a fair severance package for those who are laid off. This may not be a legal obligation, but many organizations offer severance packages to the impacted individuals to help them along this transition. Some of these packages may contain salary continuation, vacation pay, continued employer paid period of benefits coverage, employer paid health premiums, counseling, retraining, resume building, interviewing skills, and more.

Another important step is regularly meeting with the remaining workforce to transmit a sense of trust and to keep up the morale of the company. Layoffs are a very traumatic experience for the individuals affected directly, as well as for the 
ones that continue in the organization, and for the management. Therefore, it is crucial to have the HR department carefully orchestrate this process to minimize the negative consequences and position the company for a successful financial journey throughout the layoff process.

\section{VSO ${ }^{1}$ in Practice}

After watching and observing the early retirement of 21 experienced faculty colleagues from the college of business in South Florida during May-June of 2018, I can especially emphasize that regular and transparent communication with those who remain in the organization is extremely important for their morale, commitment, and motivation. These faculty members retired as part of a volunteer separation option (VSO) package offered by the university in order to bring the college's fiscal budget into alignment. From a legal perspective, it is first interesting to note that the VSO package was not phrased as an offer to certain faculty to accept, but rather as an "invitation" to make an offer by the university, which the university could then accept or reject, thereby giving the university control as to who exactly would have the separation agreement. Secondly, the university made it very clear, as well it should, that if not enough faculty members took the separation package there might be layoffs. However, the layoffs would not be premised on age and/or seniority (for the obvious reason of not contravening the age discrimination act or ADEA) but rather on such "neutral" factors as course, class, and subject matter needs as well as publications.

The professors did not have to leave the institution; a severance package was offered to all eligible individuals and these faculty members "volunteered" to take it (even though, in terms of age, many were not ready for retirement yet). Nonetheless, losing so many experienced and respected colleagues (about $20 \%$ of the college's professors) during the same two-month period was a very difficult process for most of the remaining faculty. Despite the fact that the institution's chief executive officer and human resources department professionals regularly communicated with all the staff and faculty members, a few individuals felt dismayed, confused, and shocked, while some felt angry and uncertain about their future in the college. Consequently, in the months and year to follow, seven other young and bright faculty members voluntarily resigned from the college after they secured prominent teaching positions at other institutions. Two years later in early 2020, some of those terminated positions are being filled through national recruitments, interviews and campus visits of new candidates.

During the VSO period, in order to try to ameliorate any negative feelings as well as recoup some of that lost professorial talent, the university provided that the faculty members who took the separation agreement could come back to the university and teach as adjunct professors. Moreover, since there was now office space available to those professors coming back as adjuncts, though in many ${ }^{1}$ Special thanks go to all my graduate HR students during 2018 for their insights and research on layoffs and to Professor Frank J. Cavico, Nova Southeastern University, for sharing his thoughts and experiences regarding voluntary separation options. 
cases having to give up their own original offices, were given other separate (and not shared offices) with their nameplates on the door, thus symbolizing their continued presence and service to the university. As adjuncts, they also kept their university emails. Most importantly, and very commendably on the university's part, several faculty members with long-time service to the university were accorded Professor Emeritus status at a very nice luncheon and award ceremony at the university. Professor Emeritus status, of course, allowed those faculty members, even if they decided not to continue teaching as adjuncts, to have a substantial relationship with the university in all the academic, social, community, and athletic activities. Moreover, the separation agreement allowed the pertinent faculty members to choose whether to receive the monetary benefits from the separation package in one lump sum or spread out over four payments over a three-year period, thereby affording the faculty members some flexibility in tax planning.

Having gone through this VSO experience, one can say with one-hundred percent certainty that effective communication is very important for those who are leaving the organization, and even more critical for those who remain. Since the entire college or department's culture is changing and people's teaching responsibilities and assignments are impacted, it is very important that all faculty members and staff be informed of and engaged in the transition process. Equally important was the meritorious effort by the university to make the faculty affected by the separation agreement feels that they were still part of the department, college, school, and university community. For psychological, practical, ethical, as well as legal reasons that was the "right" and the "smart" thing for the university to do.

\section{Summary}

Most "People don't mind change; but they mind being changed." Consequently, ownership of the change is more difficult to create for a layoff, especially if employees are not involved in the decision-making process from the outset. Therefore, the lesson is to involve and engage both managers and employees as early in the layoff process as possible. Layoffs and downsizing can provide senior managers and human resources professionals with options that can significantly improve the company's competitive position in the industry.

Downsizing allows the company to clear up the organization for restructuring as well as for bringing fresh and innovative new ideas. Many times, layoffs can be beneficial to purge the entire organization of excessive, redundant, disengaged, and/or underperforming employees in order to establish some form of control and stability moving forward. Layoffs and downsizing may be most necessary or useful for organizations that have experienced scandals or are not competitive. Finally, through effective management, leadership, and implementation of layoff policies, human resources professionals can demonstrate how valuable they can be to the overall strategic direction of the company moving forward. 
Overall, human resources professionals can and must play a vital leadership role in structuring and implementing an organization's layoff process and downsizing policies. As mentioned before, sometimes it is crucial for managers to make necessary cuts in the workplace while keeping in mind the needs of the organization in order to remain competitive in the market. Human resources and organizational managers should also be responsible for meeting with remaining employees that are having a difficult time adjusting to the new culture and provide relevant support that those individuals may need. An important job of human resources professionals is to boost the morale and commitment of employees who remain after the reduction.

\section{Conflicts of Interest}

The authors declare no conflicts of interest regarding the publication of this paper.

\section{References}

Acevedo, L. (2017). Disadvantages to Company Downsizing. https://smallbusiness.chron.com/disadvantages-company-downsizing-26158.html

Appelbaum, S. H., Delage, C., Labib, N., \& Gault, G. (1997). The Survivor Syndrome: Aftermath of Downsizing. Career Development International, 2, 278-286. https://doi.org/10.1108/13620439710178639

Baruch, Y., \& Hind, P. (2000). Survivor Syndrome'-A Management Myth? Journal of Managerial Psychology, 15, 29-45. https://doi.org/10.1108/02683940010305289

Bennett, J., \& Moehring, K. (2015). Cumulative (Dis)Advantage? The Impact of Labour Market Policies on Late Career Employment from a Life Course Perspective. Journal of Social Policy, 44, 213-233. https://doi.org/10.1017/S0047279414000816

Bruno, J. B. (2008). Layoffs Can Pose Both Pros, Cons. https://newsok.com/article/3293962/layoffs-can-pose-both-pros-cons

Cappelli, P., Bassi, L., Katz, H., Knoke, D., Osterman, P., \& Useem, M. (1997). Change at Work. New York: Oxford University Press.

Cavico, F. J., \& Mujtaba, B. G. (2013). Business Ethics: The Moral Foundation of Leadership, Management, and Entrepreneurship (3rd ed.). New York: Pearson.

Cavico, F. J., \& Mujtaba, B. G. (2014). Business Law for the Entrepreneur and Manager (3rd ed.). Florida: ILEAD Academy.

Cavico, F. J., Mujtaba, B. G., \& Muffler, S. (2016). Covenant-Not-To-Compete: The Relationship of Training and Education Criteria to Enforceability. SAM Advanced Management Journal, 81, 45-59.

Cheretis, D., \& Mujtaba, B. G. (2014). Maximizing Long-Term Value and Conscious Capitalism at Whole Foods. SAM Advanced Management Journal, 79, 4-16.

Cunningham, N. (2016). After 350,000 Layoffs Oil Companies Now Face Worker Shortages.

https://oilprice.com/Energy/Energy-General/After-350000-Layoffs-Oil-Companies-No w-Face-Worker-Shortages.html

Datta, D. K., Guthrie, J. P., Basuil, D., \& Pandey, A. (2010). Causes and Effects of Employee Downsizing: A Review and Synthesis. Journal of Management, 36, 281-348. https://doi.org/10.1177/0149206309346735 
David, C. (2011). How Conducting a Job Analysis Improves Your Business's Efficiency, Growth and Innovation.

http://www.sbnonline.com/article/how-conducting-a-job-analysis-improves-your-busi nesss-efficiency-growth-and-innovation/

George, J. M. (2014). Compassion and Capitalism: Implications for Organizational Studies. Journal of Management, 40, 5-15. https://doi.org/10.1177/0149206313490028

Heathfield, S. M. (2019). Here Is a Look at the Effects of Downsizing on Surviving Employees.

https://www.thebalancecareers.com/how-employees-respond-to-change-after-layoffs-1 918585

Jordan, A. H., \& Zitek, E. M. (2012). Marital Status Bias in Perceptions of Employees. Basic and Applied Social Psychology, 34, 474-481.

https://doi.org/10.1080/01973533.2012.711687

Kokemuller, N. (2016). The Disadvantages of a Layoff. https://yourbusiness.azcentral.com/disadvantages-layoff-4178.html

Kokemuller, N. (2017). How Is a Layoff Positive for a Business? https://smallbusiness.chron.com/layoff-positive-business-66493.html

Kurebwa, J. (2011). Organisational Downsizing and Its Impact on Leavers and Survivors: The Case of the Reserve Bank of Zimbabwe. Journal of Emerging Trends in Economic and Management Sciences, 2, 264-269.

Latack, J. C., Kinicki, A. J., \& Prussia, G. E. (1995). An Integrative Process Model of Coping with Job Loss. Academy of Management Review, 20, 311-335.

https://doi.org/10.5465/amr.1995.9507312921

Liu, D., Gong, Y., Zhou, J., \& Huang, J. C. (2017). Human Resource Systems, Employee Creativity, and Firm Innovation: The Moderating Role of Firm Ownership. Academy of Management Journal, 60, 1164-1188. https://doi.org/10.5465/amj.2015.0230

Lynch, D. J., \& Telford, T. (2018). GM Layoffs and Plant Shutdowns Suggest U.S. Economy May Be Starting to Slow-And Dent Trump's Claim of an Industrial Renaissance. The Washington Post.

https://www.washingtonpost.com/business/economy/gm-layoffs-and-plant-shutdowns -suggest-us-economy-may-be-starting-to-slow--and-dent-trumps-claim-of-an-industri al-renaissance/2018/11/26/39533566-f1ba-11e8-80d0-f7e1948d55f4 story.html?noredir ect=on\&utm term=.a1b996cb575d

Mannino, B. (2010). The Pros of Layoffs. Fox Business. https://www.foxbusiness.com/features/the-pros-of-layoffs

Mossholder, K. W., Settoon, R. P., Armenakis, A. A., \& Harris, S. G. (2000). Emotion during Organizational Transformations. An Interactive Model of Survivor Reactions. Group and Organization Management, 25, 220-243. https://doi.org/10.1177/1059601100253002

Mujtaba, B. G. (2010). Workforce Diversity Management: Challenges, Competencies and Strategies (2nd ed.). Davie, FL: ILEAD Academy.

Mujtaba, B. G. (2014). Managerial Skills and Practices for Global Leadership. Davie, FL: ILEAD Academy.

Mujtaba, B. G. (2019). Leadership and Management Philosophy of "Guzaara” or Cooperating to "Get Along" in South Asia's Afghanistan. Business Ethics and Leadership, 3, 44-57. https://doi.org/10.21272/bel.3(1).44-57.2019

Mujtaba, B. G., \& McCartney, T. (2010). Managing Workplace Stress and Conflict amid Change (2nd ed.). Davie, FL: ILEAD Academy. 
Mujtaba, B. G., Ping, H., \& Jieqiong, C. (2013). A Cross-Cultural Analysis of Management Skills with Chinese, Iranian, Pakistanis, Thai, and American Managers. SAM Advanced Management Journal, 78, 50-67.

Neto, S. (2018). Perceived Acceptability of Organizational Layoffs and Job Alliances during a Recession: A Mapping of Portuguese People's Views. Journal of Business Ethics, 152, 1149-1157. https://doi.org/10.1007/s10551-016-3270-Z

Noe, R. A., Hollenbeck, J. R., Gerhart, B. \& Wright, P. M. (2018). Human Resource Management: Gaining a Competitive Advantage (11th ed.). New York: McGraw-Hill.

Perlman, K. (2014). How to Lead after Layoffs: Learning from Microsoft. https://www.forbes.com/sites/johnkotter/2014/09/22/leading-after-layoffs-learning-fro m-microsoft/\#5900f8327f81

Petzall, B. J., Parker, P. E., \& Stoeberl, P. (2000). Another Side to Downsizing: Survivors' Behavior and Self-Affirmation. Journal of Business Psychology, 14, 593-603. https://doi.org/10.1023/A:1022990214073

Ramlall, S. J., Al-Sabaan, S., \& Magbool, S. (2014). Layoffs, Coping, and Commitment: Impact of Layoffs on Employees and Strategies Used in Coping with Layoffs. Journal of Management and Strategy, 5, 25-30. https://doi.org/10.5430/jms.v5n2p25

Reddy, C. (2018). Advantages and Disadvantages of Downsizing Employees. https://content.wisestep.com/advantages-disadvantages-downsizing-employees/

Sainato, M. (2018). They Are Liquidating Us: AT\&T Continues Layoffs and Outsourcing Despite Profits.

https://www.theguardian.com/us-news/2018/aug/28/att-earns-record-profits-layoffs-o utsourcing-continue

Sarwar, A., Khan, M. M., \& Mujtaba, B. G. (2018). Managing Despotic Leadership, Workplace Ostracism and Knowledge Hoarding: A Serial Mediation Model. Advanced Management Journal, 82, 4-19.

Schmitt, A., Borzillo, S., \& Probst, G. (2012). Don't Let Knowledge Walk Away: Knowledge Retention during Employee Downsizing. Management Learning, 43, 53-74. https://doi.org/10.1177/1350507611411630

Senathip, T., Mujtaba, B. G., \& Cavico, F. J. (2017). Policy-Making Considerations for Ethical and Sustainable Economic Development. Economy, 4, 7-14.

https://doi.org/10.20448/journal.502.2017.41.7.14

Slav, I. (2016). Did Big Oil Layoff Too Many Workers Too Quickly? https://oilprice.com/Energy/Energy-General/Did-Big-Oil-Layoff-Too-Many-WorkersToo-Quickly.html

SmartTalk HR (2019). Rise Smart. https://www.risesmart.com/blog/3-ways-hr-can-make-strategic-impact-during-layoff

Telford, T. (2018). GM to Lay off 15 Percent of Salaried Workers, Halt Production at Five Plants in U.S. and Canada.

https://www.washingtonpost.com/business/2018/11/26/gm-lay-off-percent-salaried-

Travaglione, A., \& Cross, B. (2006). Diminishing the Social Network in Organizations: Does There Need to Be Such a Phenomenon as 'Survivor Syndrome' after Downsizing? Strategic Change, 15, 1-13. https://doi.org/10.1002/jsc.743

Uhlig, D. K. (2017). How Does Downsizing Impact the Role of Human Resource Management?

https://smallbusiness.chron.com/downsizing-impact-role-human-resource-manageme nt-38669.html

University of Washington (2018). Layoff and Reduction. 
https://hr.uw.edu/ops/ending-employment/layoffs/layoff-and-reduction/

Varelas, E. (2010). 10 Strategies for Dealing with Layoffs. HR Exchange Network. https://www.hrexchangenetwork.com/hr-talent-management/articles/10-strategies-fordealing-with-layoffs

Wolf, F., \& Mujtaba, B. G. (2011). Sustainability in Service Operations. International Journal of Information Systems in the Service Sector, 3, 1-20. https://doi.org/10.4018/jisss.2011010101

Zillman, C. (2015). The 10 Biggest Corporate Layoffs of the Past Two Decades. FORTUNE. http://fortune.com/2015/09/20/biggest-corporate-layoffs/ 